\title{
DIAGNÓSTICO DA DEGRADAÇÃO AMBIENTAL EM ÁREAS DE EXTRAÇÃO DE ARGILA EM MARABÁ - PA
}

\section{Andréa Hentz de Mello1; Marcus Felipe Frota Gama²; Gustavo Ferreira de Oliveira33; Jairo Cosme da Silva 4 .}

\author{
Universidade Federal do Sul e Sudeste do Pará (UNIFESSPA), Marabá, Pará, andreahentz@unifesspa.edu.br \\ UNIFESSPA, Marabá, Pará, adm@hotmail.com \\ UNIFESSPA, Marabá, Pará, gustavo_mania21@hotmail.com \\ UNIFESSPA, Marabá, Pará, junimg12@unifesspa.edu.br
}

RESUMO: As cerâmicas instaladas no município de Marabá - PA, cujas atividades representam impactos para o meio ambiente são pressionadas pelo governo, pela legislação e pela opinião pública a adotarem medidas concretas de preservação e controle ambiental. Considerando, portanto as alterações que a atividade de mineração de argila pode causar nas formas de relevo e paisagem e na dinâmica territorial da população bem como a necessidade de recuperação das áreas degradadas, este trabalho teve como objetivo identificar os impactos ambientais em decorrência da ação da atividade industrial de mineração de argila e verificar como esta atividade afeta a realidade socioambiental da população ao entorno dos empreendimentos. Este trabalho alertou a respeito da questão dos passivos ambientais oriundos da extração de argila, importante recurso mineral destinado à construção civil que o Brasil figura entre os maiores exportadores mundiais. Consequência de tal fato se refere às contrapartidas ambientais que se encerram diante da exploração, e que se impõe em diferentes modalidades de impactos no meio físico, conforme a natureza do material extraído e as condições de exploração.

PALAVRAS-CHAVE: Fiscalização, Medidas compensatórias, Produção industrial.

\section{DIAGNOSTICS OF ENVIRONMENTAL DEGRADATION IN ÁREAS OF CLAY EXTRACTION IN MARABÁ - PA}

ABSTRACT: Ceramics installed in the municipality of Marabá - PA, whose activities represent impacts on the environment, are pressured by the government, by legislation and by public opinion to adopt concrete measures of preservation and environmental control. Considering, therefore, the alterations that the clay mining activity can cause in the forms of relief and landscape and in the territorial dynamics of the population as well as the need of recovery of the degraded areas, this work had the objective to identify the environmental impacts as a result of the action of the Industrial activity of clay mining and to verify how this activity affects the socio-environmental reality of the population to the surroundings of the enterprises. This work warned about the environmental liabilities arising from the extraction of clay, an important mineral resource for civil construction that Brazil is among the largest exporters in the world. Consequence of this fact refers to the environmental counterparts that are closed before the exploration, and that is imposed in different 
modalities of impacts in the physical environment, according to the nature of the extracted material and the operating conditions.

KEYWORDS: Compensatory measures, Industrial production, Inspection.

\section{DIAGNÓSTICO DE LA DEGRADACIÓN AMBIENTAL EN ÁREAS DE EXTRACCIÓN DE ARCILLA EN MARABÁ - PA}

RESUMEN: Las cerámicas instaladas en el municipio de Marabá - PA, cuyas actividades representan impactos para el medio ambiente son presionadas por el gobierno, la legislación y la opinión pública a adoptar medidas concretas de preservación y control ambiental. Considerando, por lo tanto, las alteraciones que la actividad de minería de arcilla puede causar en las formas de relieve y paisaje y en la dinámica territorial de la población así como la necesidad de recuperación de las áreas degradadas, este trabajo tuvo como objetivo identificar los impactos ambientales como consecuencia de la acción de la acción Actividad industrial de minería de arcilla y verificar cómo esta actividad afecta la realidad socioambiental de la población al entorno de los emprendimientos. Este trabajo alertó sobre la cuestión de los pasivos ambientales provenientes de la extracción de arcilla, importante recurso mineral destinado a la construcción civil que Brasil figura entre los mayores exportadores mundiales. La consecuencia de tal hecho se refiere a las contrapartidas ambientales que se cierran ante la explotación, y que se impone en diferentes modalidades de impactos en el medio físico, conforme a la naturaleza del material extraído y las condiciones de explotación.

PALABRAS CLAVE: Fiscalización, Medidas compensatorias, Producción industrial.

\section{INTRODUÇÃO}

A mineração é definida como a extração, elaboração e beneficiamento de minerais que estão em estado natural. São inclusos também a exploração das minas subterrâneas e a céu aberto, as pedreiras e os poços, com todas as atividades complementares para preparar e beneficiar minérios e outros minerais em bruto (REGENSBURGER, 2004). É uma atividade de extrema importância para a economia de muitos países, porém, segundo Farias (2002), requer responsabilidade social, uma vez que deve levar em conta a questão do desenvolvimento sustentável.

Devido à extração de argila e os depósitos de rejeitos oriundos da mesma, as formas de relevo locais são alteradas, resultando numa série de outras alterações indiretas como no caso dos processos morfológicos presentes, que envolvem mudanças de direção de fluxos das águas de escoamento superficial, fazendo com que as áreas que estão dominadas pelos efeitos erosivos se transformem em ambientes de deposição ou vice-versa (ANJOS et al., s/d apud COLTURATO, 2002). 
A retirada de argila ocorre preferencialmente nos meses de menor precipitação, devido à maior facilidade das condições de acesso e do próprio trabalho de exploração. A argila é extraída geralmente a céu aberto, devido aos depósitos sedimentares estarem situados próximo à superfície, cobertos por camadas de solo de pequena espessura. O método mais utilizado para tal é o de lavra, que consiste no desmonte mecânico das camadas de argila por tiras ou cavas semicirculares. Os equipamentos utilizados são: a pá-carregadeira, a escavadeira ou retroescavadeira, os quais são escolhidos de acordo com a forma e profundidade do extrato argiloso (ANJOS et al., s/d apud COLTURATO, 2002).

Para ser realizada a exploração mineral, a vegetação deve ser eliminada no começo das atividades de lavra. Em relação ao solo, é retirado os horizontes $A$ e parte do $B$, pois o material de interesse se encontra próximo ao horizonte $C$ e uma parte no B. Assim, a superfície do solo fica mais exposta à ação do impacto das gotas de chuva, o que contribui na modificação de suas condições físicas, induzindo o processo de compactação do solo e alterando a rugosidade superficial, a porosidade e a taxa de infiltração da água. Isso causa um distúrbio considerável no ambiente, onde torna-se necessário a intervenção humana para criar condições para que a vegetação possa se recuperar, implicando em custos financeiros e legais, uma vez que é necessário atender a legislação ambiental (ALBUQUERQUE, 2002; REGENSBURGER, 2004).

Segundo Salvador e Miranda (2007), a intensidade da degradação de uma área depende do volume, do tipo de mineração e dos rejeitos produzidos. A recuperação das áreas deve ser considerada como parte do processo de mineração. De acordo com a Lei No 6938/1981 (Política Nacional do Meio Ambiente), diante dos efeitos negativos causados pelas ações humanas é necessária à implantação de um Plano de Recuperação de Áreas Degradadas (PRAD). Este plano envolve as ações a serem desenvolvidas no local, cujo objetivo é promover o retorno de algum tipo de uso da área que foi degradada. $\bigcirc$ plano pré-estabelecido para o uso do solo busca obter estabilidade do ambiente diante dos problemas ambientais decorrentes desta atividade exploratória.

A intervenção antrópica no relevo terrestre, quando desenvolvida sem levar em consideração os aspectos conservacionistas, pode acelerar o processo de degradação ambiental. A mineração talvez seja uma das atividades que mais contribui para a alteração da superfície terrestre, afetando não somente a paisagem local, mas toda a dinâmica ecossistêmica, sendo um tema importante nos estudos da Geomorfologia, que por sua vez tem um papel fundamental no diagnóstico de determinadas áreas, além de contribuir de forma efetiva nos projetos voltados para sua recuperação (GUERRA; MARÇAL, 2006).

Ainda segundo Guerra e Marçal (2006), a contribuição da Geomorfologia para avaliação e gestão dos recursos minerais pode destacar-se em três principais tópicos: solos, minerais, areia e cascalhos. Por conta da extração destes, diversas áreas apresentam uma série de impactos ambientais entre os quais estão os riscos geomorfológicos que essa atividade econômica pode causar. Por 
conta disto, Hart (1986), apud GUERRA; MARÇAL (2006) cita quatro principais áreas em que os estudos geomorfológicos podem contribuir: 1) Identificação, mapeamento e avaliação econômica de depósitos de certos minerais; 2) Avaliação de impactos socioambientais que possam vir a ocorrer, diante da exploração de minerais; 3) Monitoramento da área em exploração, durante e após a atividade de mineração; 4) Avaliação de relação custo/benefício, advinda das operações de mineração.

Para Silva (2011), é no território que toda a ação de uma sociedade se evidencia e os reflexos das decisões, políticas, econômicas e sociais serão parte da configuração do espaço e suas redes de relações vão se constituindo gerando embates sociais ou não. Santos (2005) assume que o objeto da análise social é o uso do território, e não o território em si mesmo. Heidrich (2004) reforça que o território é um espaço de apropriação fruto dos processos, sociais, políticos e econômicos em desigualdade a relação do uso da natureza, produzindo formas desiguais que se apresentaram no uso do espaço e do território. O uso do espaço e do território de maneira privativa gerou um aumento na produtividade, por outro, levou a impactos ambientais indesejáveis.

A dinâmica presente, no território amazônico brasileiro é uma constante e seus reflexos são latentes na região a exemplo da Cidade de Marabá no Estado do Pará, onde as estratégias de apropriação do espaço foi se perpetuando fortemente com a implantação dos grandes projetos para a região, obedecendo a uma lógica geopolítica de ocupação e controle do território amazônico pelo Estado, associado ao grande capital interno e externo, promovendo assim, o aumento do impacto socioambiental.

Para Monteiro (2006), "a implantação de novas atividades econômicas pode elevar os níveis de produção de uma região ou de uma localidade sem que, entretanto, ocorra um processo de desenvolvimento econômico e social". É sobre essa perspectiva que os empreendimentos de extração mineral de argila vêm se desenvolvendo na região, em especial na cidade de Marabá-PA.

A exploração industrial de argila na cidade de Marabá tem causado uma série de impactos negativos ao meio socioambiental. A descaracterização da paisagem já mencionada sempre é o primeiro impacto a ser notado nos empreendimentos de extração de argila

Considerando, portanto as alterações que a atividade de mineração de argila pode causar nas formas de relevo e paisagem e na dinâmica territorial da população bem como a necessidade de recuperação das áreas degradadas, este trabalho teve como objetivo identificar os impactos ambientais em decorrência da ação da atividade industrial de mineração de argila e verificar como esta atividade afeta a realidade socioambiental da população ao entorno dos empreendimentos.

\section{MATERIAL E MÉTODOS}

Marabá está inserida na mesorregião Sudeste Paraense apresentando as seguintes coordenadas geográficas: $05^{\circ}$ 21' 54"Latitude Sul e 04 07' 24" Longitude WGr sendo banhada pelos rios Tocantins e Itacaiúnas. $O$ acesso à cidade pode ser feito por via aérea, rodoviária e ferroviária. O principal acesso rodoviário pode ser 
efetuado através de estrada PA-150. A sua principal avenida de integração central é a rodovia Transamazônica que integra a cidade e seus principais bairros conhecidos como Cidade Nova, Marabá Pioneira e Nova Marabá (ALMEIDA, 2007) apresentando uma área de 15157,9 Km², onde vivem aproximadamente 257.062 habitantes (IBGE, 2010).

As áreas de extração de argila que compreendem este estudo estão inseridas às margens do rio Itacaiúnas e são denominadas de Cerâmica Cerita e Cerâmica Bambu. A área de extração da Cerâmica Cerita está localizada no núcleo Cidade Nova na Planície de Inundação do Rio Itacaiúnas, bairro Novo Horizonte, apresentando uma área total de 11,6 ha, área de exploração: 11,6 ha, latitude: $05^{\circ}$ $22^{\prime} 32,544^{\prime \prime}$ (-S), longitude: 490 05' 56,790" (-W), com produção estimada de 12.000 toneladas/ano.

A área de extração da Cerâmica Bambu está localizada na Rua Boa Vista $s / n$, bairro Jardim União, núcleo Cidade Nova, apresentando uma área total de 10,48 ha, área de exploração: 10,48 ha, latitude: $05^{\circ} 20^{\prime} 53^{\prime \prime}(\mathrm{S})$, longitude: $49^{\circ} 06^{\prime}$ 02" (W), distância: 6077 m no rumo $25^{\circ}$ 42'16" (SW), com produção estimada de 13.526,1 toneladas/ano.

As mesmas apresentarem passivos ambientais, planos de reabilitação das áreas exploradas (PRADs) e operarem na área urbana da cidade de Marabá, apresentando assim, características que se enquadram na proposta de pesquisa. As áreas de extração de argila estão inseridas na região que apresenta clima dos tipos Am (tropical úmido e monção) e Aw (tropical úmido), segundo a classificação de Köppen, com base, principalmente, nas precipitações pluviométricas e nas temperaturas.

O período chuvoso é notório de dezembro a maio e o mais seco, de junho a novembro, estando 0 índice pluviométrico em torno de 2.000 $\mathrm{mm} / \mathrm{ano}$. A umidade relativa do ar é elevada, oscilando entre as estações mais chuvosas a mais seca. Segundo a classificação climática de Thorntwaite que considera os índices representativos de umidade, aridez e eficiência térmica, diretamente derivados da precipitação pluviométrica e da temperatura - a cidade de Marabá enquadra-se em uma região de clima úmido e subúmido. A área apresenta temperatura média mínima, anual, de $10^{\circ} \mathrm{C}$ a $26^{\circ} \mathrm{C}$ e média máxima de $25^{\circ} \mathrm{C}$ a $35^{\circ} \mathrm{C}$, com a umidade média anual de 85\% (ALMEIDA, 2007).

Quanto a classificação morfológica dos solos, Rosatelli et al. (1974) caracteriza as áreas de extração de argila estão inseridas nas áreas que apresentam as seguintes unidades geológicas: a) Latossolo Vermelho Amarelo - solos de textura argilosa, profundos, bem drenados, estrutura maciça e fertilidade natural baixa. Ocorre na parte norte da cidade, em área de domínio da Formação Itapecuru e das coberturas tércioquaternárias; b) Argissolo VermelhoAmarelo - solos de textura argilosa e arenosa, rasos, bem drenados, estrutura maciça e fertilidade natural muito baixa. Tem sua origem a partir da alteração de rochas dos cinturões Itacaiúnas e Araguaia, e de uma pequena área pertencente a unidades da Bacia do Parnaíba; c) Solos Aluviais e Hidromórficos - Aluviões Eutróficos - essa unidade é constituída de solos com textura indiscriminada, medianamente profunda, 
moderadamente drenada, estrutura também indiscriminada e maciça, e de fertilidade natural, variando de média a alta. Ocorrem nos flats aluviais dos principais rios como Tocantins e Itacaiúnas.

Para a identificação dos impactos ambientais, visitas foram realizadas nas áreas de extração de argila, e visualmente foram identificados os impactos causados pela extração de argila, sendo fotografada todas as cavas de argilas, caminhões transportando a argila, área com lixo e derrubada da vegetação.

Os dados identificados no campo foram processados e apresentados na forma de tabelas, gráficos e discussões.

\section{RESULTADOS E DISCUSSÃO}

IDENTIFICAÇÃO DOS IMPACTOS SOCIOAMBIENTAIS NAS ÁREAS DE EXTRAÇÃO DE ARGILA.

Foi observado que nas áreas de extração de argila das Cerâmicas Ceritta e Cerâmica Bambu, tensões nas esferas socioambientais são potencializadas pela grande proximidade que estes empreendimentos possuem na sua base de influencia direta ao centro urbano da cidade de Marabá. Os conflitos sociais evidenciados são decorrentes da depreciação dos imóveis com proximidade das áreas de extração, a intensificação do trafego de veículos pesados causando trepidações e abalos nas estruturas prediais, ocasionando a suspensão de partículas e poeiras nocivas à saúde da população do entorno ao empreendimento, interferindo também na dinâmica local dos bairros afetados.

Ferreira et al. (2013) relatam que moradores das áreas ao entorno de áreas de extração de argila no bioma Mata Atlântica, citam problemas de saúde e desconforto em relação a geração de ruído e emissão de "poeira" (material particulado) decorrentes da extração de argila.

Kemerich et al. (2011) em estudo realizado na cidade de Santa Maria no Rio Grande do Sul, também verificaram fluxo intenso de caçambas, as quais se moviam várias vezes ao dia seguindo o trajeto área de depósito externo/empresa, gerando material particulado significativo.

Nas áreas de extração de argila das cerâmicas Ceritta e Bambu, devastação das matas ciliares e áreas de preservação permanentes (APPs) são notórias. Em algumas áreas, além do desmatamento há também a queima da vegetação, para deixar o terreno em melhores condições para a realização do trabalho de lavra. A prática da queimada afugenta o pequeno resquício de fauna que existe nessas áreas.

A retirada da vegetação deixa a área sem nenhuma cobertura, isso facilita a ação dos agentes climáticos, principalmente a chuva, que pela ação da gravidade provoca erosão, lixiviação e transporte do solo para dentro do rio Itacaiúnas, além de causar um empobrecimento do terreno, pela perda de nutrientes orgânicos e físico-químicos, compactação do solo devido ao trafego intenso de máquinas pesadas (tratores e caçambas) e a longa exposição do mesmo, após a remobilização (SANTOS; HENTZ 2014).

Nas áreas estudadas, observou-se uma significante alteração na topografia, caracterizada por dezenas de cavas. Essas cavas possuem tamanhos variados, algumas medem cerca de 3 metros de comprimento por 2 metros de 
profundidade, mas existem situações, onde essas cavas chegam a dezenas de metros de comprimento e a profundidade chega até 6 metros. As cavas abertas e abandonadas representam um risco eminente para as comunidades locais, que habitam ás áreas próximas às essas cavas.

Estes dados corroboram com os de Santos e Hentz (2014) que verificaram que esses locais servem de áreas de lazer para as crianças, que brincam nas bordas dessas cavas, que não possuem nenhuma proteção, seja ela natural ou artificial. As cavas abandonadas encontram-se em sua maioria, alagadas, formando grandes lagos, que permanecem nesse estado o ano inteiro. A situação se agrava no período chuvoso, quando essas cavas transbordam devido às águas da chuva e pelo aumento do nível do rio Itacaiúnas, que recobre toda a área, inviabilizando assim, o acesso e os trabalhos de extração de argila.

Para as cavas que permanecem alagadas, mesmo no período de estiagem foram levantadas as seguintes hipóteses: o solo argiloso que é impermeável, não deixa a água infiltrar, com isso a água fica estagnada, a segunda hipótese refere-se à profundidade das cavas, pois quanto maior a profundidade o processo de evaporação não consegue secá-las, por fim a última hipótese está relacionada com a interceptação do aquífero, que acontece durante os trabalhos de lavra. Ao nosso entender essa hipótese é a mais explicável, pois a as cavas só permaneceriam alagadas se houvesse uma manutenção constante de água, isso só poderia acontecer por meio do aquífero. Outro problema relacionado com a formação dos lagos diz respeito à saúde da população, pois, as águas paradas servem de "criatório natural" para a reprodução de mosquitos transmissores de malária, dengue e outras endemias e ainda pode provocar micoses e outras dermatoses nas pessoas que possam ter contato direto com essa água.

Este resultado, corrobora com os de Ferreira et al. (2012) que identificaram passivos ambientais decorrentes da extração de argila na Mata Atlântica, como as identificadas neste trabalho, destacando com grande notoriedade a modificação da paisagem local.

O processo de ocupação imobiliário foi observado na área de extração de argila da Cerâmica Cerita, impedindo a extração de argila, bem como o processo de reabilitação através do plantio das mudas arbóreas nativas.

Ferreira et al. (2012) também observaram a extração de argila em área de pecuária e em cultivo de café, o que promove a redução das áreas agrícolas, modificando as formas de uso e ocupação do solo com a atividade de extração do mineral, comprometendo a capacidade produtiva dos solos, e induzindo a busca por novas fronteiras agrícolas aumentando assim, a pressão sobre desmatamento de novas áreas no bioma Mata Atlântica.

Com a ocupação da área da Cerâmica Ceritta por moradores, o processo de reabilitação está interrompido momentaneamente. Embora, conforme discutido por Sánchez (2008), as obrigações ambientais para a reabilitação destas áreas sejam das indústrias que extraem os recursos minerais, e que por não existir lei infraconstitucional específica o tema vem sendo tratado pelo Decreto Federal No 
97.632, de 10 de março de 1989 (BRASIL, 1989), que disciplina a recuperação de áreas degradadas após a extração de argila ou outro mineral. É importante mencionar também que, o art. 55, § único da Lei de Crimes Ambientais (BRASIL, 1998) define como crime e infração administrativa, sujeita à penalidade de multa, o fato de deixar de recuperar a área minerada nos termos da determinação do órgão ambiental competente. Desta forma o Ministério Público do Pará, e o IBAMA já notificaram os proprietários da Cerâmica, e uma solução judicial está sendo buscada junto aos órgãos competentes.

Ferreira et al. (2012) também observaram que algumas áreas já exploradas pela extração de argila no bioma Mata Atlântica estão sendo reabilitadas, com plantio de árvores, no entanto, quando a iniciativa é tomada, reflete mais como resposta a uma exigência dos órgãos ambientais. Todavia, o plantio de espécies da flora para a reabilitação das áreas, vem ocorrendo com o plantio de espécies exóticas. Esse procedimento segundo Valicheski et al. (2009) poderá trazer risco de transformação em espécies invasoras, e consequente danos ecológicos.

A presença de lixo e entulho de restos de construções também são encontrados em grande quantidade nestas áreas (Figura 1), caracterizando mais uma ação antrópica e poluidora do meio ambiente.

Figura 1. Presença de entulho e restos de construções na área ocupada pelos moradores na área de extração de argila da cerâmica Cerita, Marabá, PA.

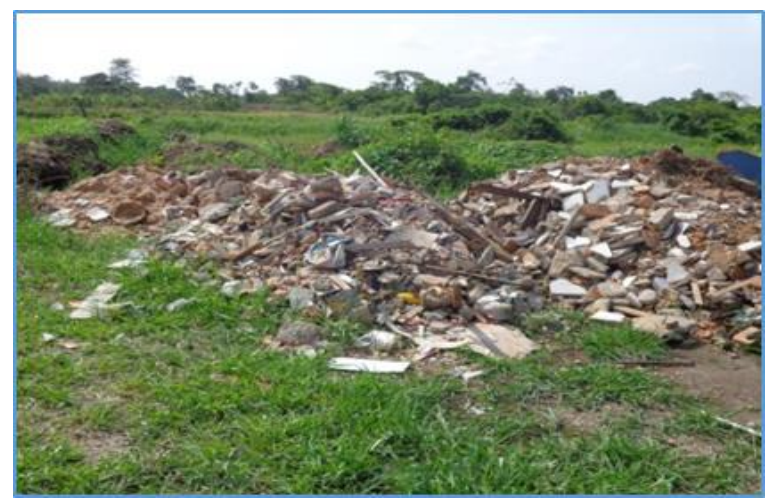

Fonte: Elaborado pelo Autor.

Isso se deve ao crescimento de acelerado e desordenado das cidades, trazendo, muitas vezes, consequências irreparáveis ao meio ambiente e à sobrevivência do ser humano (ALVES, 2011). Para Cunha e Guerra (2005) "Os problemas ambientais (ecológicos e sociais) não atingem igualmente todo o espaço urbano". Atingem muito mais os espaços físicos de ocupação das classes

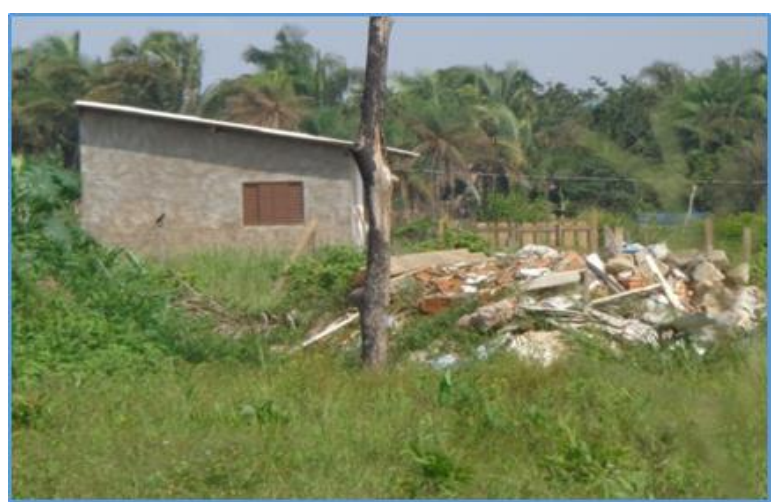

sociais menos favorecidas do que os das classes sociais mais elevadas.

É de extrema importância que os resíduos sejam devidamente coletados e depositados em locais adequados, o processo de coleta deve ser conduzido por profissionais especializados destinados a esta função (ROSA et al., 2010). A exposição direta e inadequada a esses resíduos pode apresentar diferentes 
tipos de riscos de saúde humana e ambiental (NUNES et al, 2006).

A urbanização voltada para questões ambientais vem ganhando destaque e um dos focos de concentração nessa discussão encontra-se o debate entre a questão do desenvolvimento econômico, o uso tecnológico aplicado dos grandes centros urbanos e seus reflexos socioambientais.

As cidades e sua população estão em um desafio constante com seu espaço, sofrendo com problemas locais, reivindicando infraestrutura, lazer e trabalho. A exemplo da proliferação de assentamentos da reforma agrária e dos movimentos dos sem teto sobre encostas, à beira dos rios, córregos, nas áreas de proteção ambiental e proteção permanente - APP, com precariedades urbanísticas, sem saneamento básico, com altas vulnerabilidades sociais e riscos ambientais, são facilmente percebidos. Assim, para Becker (2003) o crescimento populacional na Amazônia não foi acompanhado pela implementação de serviços básicos essenciais que garantissem o mínimo de qualidade e seguridade para a maioria dos habitantes das cidades.

Em Marabá - PA os empreendimentos industriais de mineração de argila estão constantemente influenciados por perspectivas espaciais, baseada em padrões de localização a exemplo da área de extração de argila da Cerâmica Bambu, localizada à margem esquerda da planície do Rio Itacaiúnas no bairro Cidade Nova, com uma produção de extração de 13.526, 1 toneladas/ano, atuando de forma significativa com proximidade ao leito do rio Itacaiúnas, ocasionando mudanças topográficas (surgimento de cavas), desmatamentos, tanto as ciliares, áreas de preservação permanentes - APPs, quanto às matas nativas onde estão localizados os depósitos residuais (figura 2).

Figura 2. Desmatamento da cobertura vegetal cerâmica Bambu, Marabá, PA.

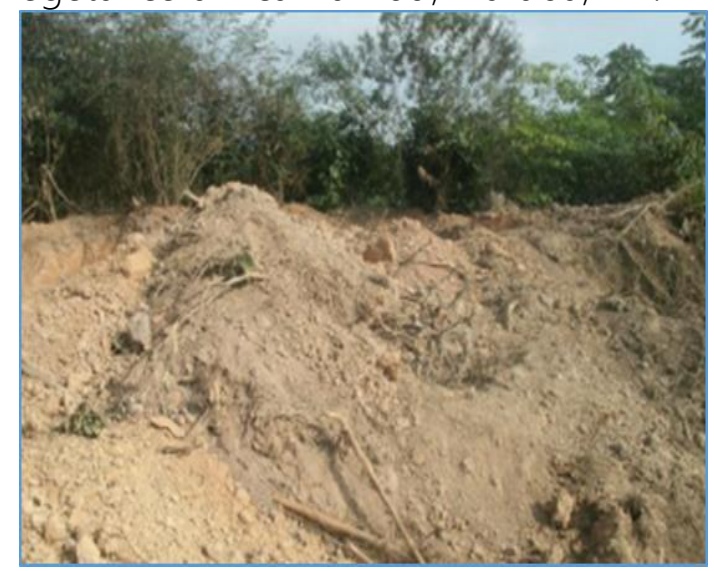

Fonte: Elaborado pelo Autor.

A atuação dos agentes mineradores em proximidade ao centro urbano da cidade e em áreas de preservação de acordo com as reflexões de Lipietz (1987) são reflexos da procura e do desenvolvimento do espaço e das relações que este proporciona com o modo de produção capitalista, seus desdobramentos espaciais e impactos no plano das relações sociais. Segundo o autor, é estruturado pelo capital e a estratégia de localização é definida pelos interesses privados e não por um pensar da equidade social. A caracterização e definição do uso do espaço também apresentam o Estado como detentor e responsável pela organização do territorial, e que traz consigo problemas que não se resolvem no plano de mecanismos do mercado.

Dessa forma, o espaço urbano vai se configurando e deflagrando contradições que refletem o modo de produção 
capitalista, que busca formas de sustentar seu mecanismo produtivo a partir do modelamento do espaço com seus interesses o que irá convergir em contradições e conflitos em suas dimensões sociais e ambientais (SANTOS 1994; LIPIETZ, 1987).

$\mathrm{O}$ art. $2^{\circ}$ da resolução n. 1/86 do Conselho Nacional do Meio Ambiente CONAMA exemplifica diversas atividades que podem gerar impactos ao meio ambiente. Essas atividades geradoras de risco, para serem executadas dependem obrigatoriamente da elaboração de estudo técnico-científico de impacto ambiental, para que os seus executores, assim, possam requerer o licenciamento devido.

Dessa forma, a realização dos estudos de impactos ambiental - EIA para os empreendimentos de mineração são importantes na tentativa de minimização dos impactos existentes, pois os empreendimentos de mineração são pressionados pelo governo, pela legislação e pela opinião pública a adotarem medidas concretas de preservação e controle ambiental. Diante dessa realidade, O EIA inicialmente tratará da identificação dos principais problemas, causas, evolução e o relatório de impacto ambiental - RIMA as informações do empreendimento como é atualmente a região juntamente com as consequências positivas e negativas e outros aspectos relacionados em um programa contínuo de monitoramento ambiental.

Como a problemática socioambiental não está relacionada apenas aos empreendimentos ceramistas, a conscientização dos empresários e da comunidade em geral, a fim de criar uma cultura de preservação e uso racional dos recursos naturais, é de fundamental importância para qualquer projeto de caráter ambiental.

A recuperação e ou reabilitação das áreas degradadas, conforme previsto no art. 225 da Constituição Federal, é medida que deve ser veementemente cobrada do empreendedor contemplado pelo licenciamento, sob pena deste, uma vez negligenciada as exigências relativas ao meio ambiente, sofrer todas as sanções previstas no aparato jurídico.

Nas áreas de extração de argila em Marabá, pertencentes aos proprietários que participam do Convênio firmado entre sindicato das Cerâmicas Vermelhas de Marabá e Região (SINDCERV) E Universidade Federal do Pará (UFPA), objeto deste trabalho, esta reabilitação vem ocorrendo desde 2009, no entanto, ainda há disputas entre o espaço/território e a população, constituindo-se em ocupação como no caso nas áreas de extração das Cerâmicas Bambu, Dezém e Cerita.

A população local, muitas vezes não tem consciência de que estas áreas são improprias para moradia, uma vez que estas áreas estão sob influência de solos extremamente argilosos, do lençol freático e das cheias dos rios Tocantins e Itacaiúnas durante o inverno Amazônico. Entretanto, ocupam estas áreas, sob a alegação de falta de espaço para construírem suas moradias e que os empresários estão explorando as áreas de forma ilegal, gerando aí, conflitos entre os empresários e a população. 
REFLEXÕES NA PRODUÇÃO DE ESPAÇOS URBANOS SEGREGADOS NA CIDADE DE MARABÁ - PA

A cidade de Marabá, no contexto atual, pressupõe ser resultado de uma multidimensionalidade de ações tanto políticas e econômicas quanto sociais que historicamente vem modificando a geografia da região e acerca de alguns momentos significativos desenham uma compreensão do processo de modificações da rede urbana (COELHO et al., 1997).

A estruturação da cidade de Marabá, uma vez, inserida no contexto de divisão territorial do trabalho e de integração da Amazônia ao Centro-Sul do Brasil, gera uma ruptura no que diz respeito à substituição do padrão de organização do espaço amazônico, baseado nas atividades da produção extrativista e que constituía uma rede urbana simples; que perdurou desde o processo de colonização até aproximadamente os anos de 1950, posteriormente as políticas governamentais exerceram papel decisivo no contexto dessas transformações estruturais da rede urbana na Amazônia Oriental, a partir dos anos de 1970.

Esse papel está relacionado a uma lógica de organização do espaço amazônico que teve como características principais: a estruturação da rede rodoviária, a ação intensiva de empresas capitalistas na exploração dos recursos da região, além da presença marcante do Estado, por meio de incentivos fiscais, da criação de infraestrutura e de repartições públicas, da criação de órgãos de planejamento e financiamento como Banco da Amazônia (BASA), Superintendência de Desenvolvimento da Amazônia (SUDAM), de projetos de colonização agropecuários e agrominerais (GONÇALVES, 2004).

Para Hébette (2004), os anos de 1970 marcaram um período de muitas mudanças no espaço da cidade de Marabá - PA, com declínio da produção da castanha do Brasil (Bertholletia excelsa), em razão da derrubada de castanhais, para dar lugar à pecuária de cunho empresarial que vinha instalandose progressivamente na região.

Como resultado do processo de estruturação do espaço amazônico, novos atores sociais (empresários, fazendeiros e migrantes) passaram a inserirem-se nesta região, que já possuía uma população tradicional, composta de ex-trabalhadores dos castanhais, de excoletores independentes da castanha, além de pequenos posseiros desterritorializados (COELHO et al., 1997).

Somam-se a estes, migrantes semterra e de colonos atraídos pelos projetos de colonização às margens da Transamazônica. Diante do exposto e da configuração do cenário e do espaço no município de Marabá, a evidencia da presença de múltiplos atores sociais que em sua grande maioria apresentam-se com interesses divergentes, evidenciando que o processo de ocupação, desde seu início na região, revela-se na forma de conflitos espaciais e territoriais (Figura 3). 
Figura 3. Empreendimentos industriais de mineração de argila e bolsões de espaços segregados da região urbana da Cidade de Marabá-PA.

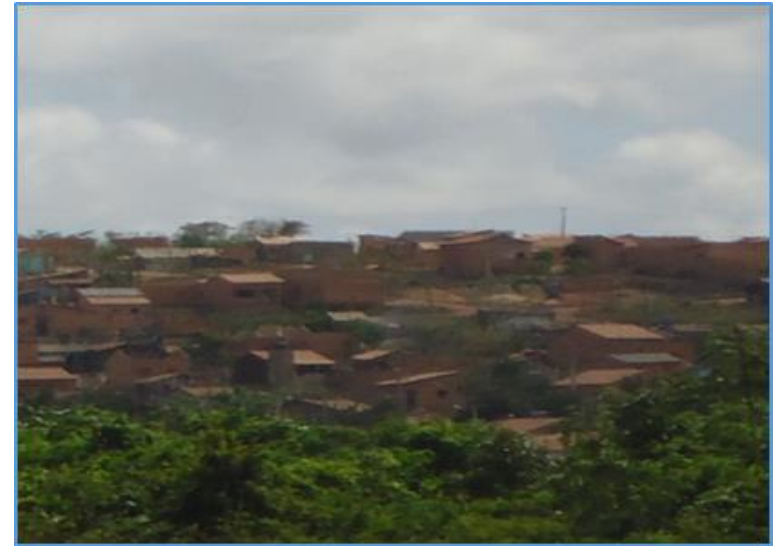

Fonte: Elaborado pelo Autor.

TERRITÓRIO E CONFLITO AMBIENTAL: CONTEXTO DA PRODUÇÃO INDUSTRIAL DE ARGILA EM MARABÁ - PA E IMPACTO AMBIENTAL

O Ministério Público do Estado do Pará fazendo uso segundo resolução do Conselho Nacional do Meio Ambiente CONAMA nº 001, em seu artigo $1^{\circ}$ - para efeito desta resolução, considera-se impacto ambiental qualquer alteração das propriedades físicas, químicas e biológicas do meio ambiente, causada por "qualquer forma de matéria ou energia resultante das atividades humanas que direta ou indiretamente afetam: a saúde, a segurança e o bem estar da população; as atividades sociais e econômicas; a biota; as condições estéticas e sanitárias do meio ambiente; a qualidade dos recursos ambientais".

Para Hentz (2012) a exploração dos recursos minerais implica diretamente em modificações ambientais na área de extração de argila, onde requer inicialmente a remoção dos horizontes superficiais do solo causando mudanças na estrutura e na atividade biológica do solo levando este ambiente à degradação.

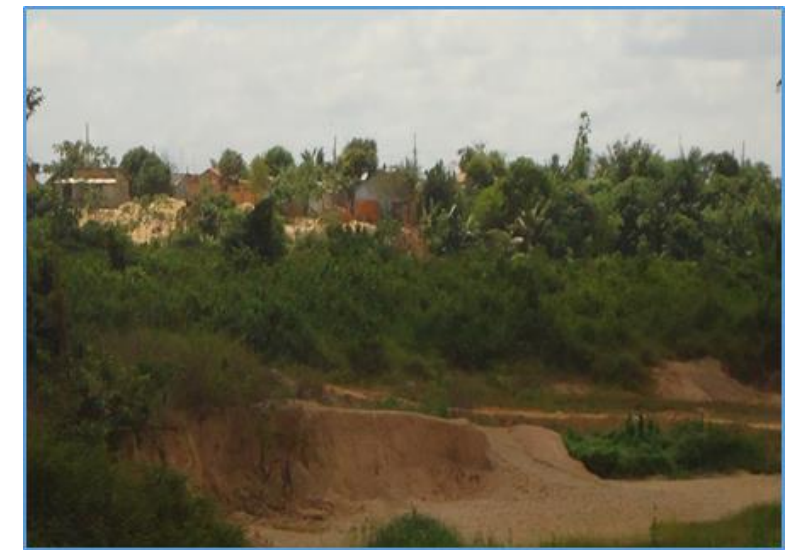

Nesse processo intencional de formatação do espaço amazônico onde está inserida a Cidade de Marabá-PA os interesses e as estratégias apresentam-se fortemente no uso e exploração da terra. Isso se dá devido à promoção de políticas de ocupação na sua grande maioria desordenadas, gerando um quadro significativo de ocupação dos espaços de forma desigual. Entretanto, as reivindicações e o passivo social existente na região são assuntos de segunda pauta. Assim, quando formas diferentes no uso do espaço se deparam os conflitos passam a existir; sejam por disputas econômicas, sociais, ambientais e territoriais no uso dos recursos existentes. Esse contexto é sensivelmente percebido quando se trata da região e suas relações de poder existentes (HALL, 1991).

As cerâmicas vermelhas instaladas no município de Marabá - PA, cujas atividades representam impactos para o meio ambiente, são pressionadas pelo governo, pela legislação e pela opinião pública a adotar medidas concretas de preservação e controle ambiental. Diante dessa realidade, a minimização dos 
impactos ambientais depende inicialmente da identificação dos principais problemas: causas, evolução, consequências e outros aspectos relacionados em um programa contínuo de monitoramento ambiental. Assim, pelo conhecimento da lógica e das especificidades dos problemas ambientais, torna-se possível definir ações verdadeiramente viáveis para reduzir os seus efeitos de modo significativo.

A proposição de ações ambientais de resultados depende de conhecimentos técnicos nesta área, e como a problemática ambiental não está relacionada apenas aos empreendimentos ceramistas, a conscientização dos empresários e da comunidade em geral, a fim de criar uma cultura de preservação e uso racional dos recursos naturais, é de fundamental importância para qualquer projeto de caráter ambiental. Contudo, a execução e - sucesso de ações desta natureza dependem de diretrizes adotadas a partir do conhecimento sistêmico da problemática ambiental e dos fatores nela atuantes.

A maioria das áreas em que são realizadas atividades de extração de argila em Marabá - PA encontram-se degradadas, devido a retirada da vegetação natural, o que facilita o processo de erosão, com considerável quantidade de rejeitos, prejudicando também a microbiota do solo que tem papel fundamental na ciclagem de nutrientes, e mananciais de água, como as margens do Rio Itacaiúnas em Marabá.

Quando a mineração se refere a uma atividade de longa data, anterior ao estabelecimento do aparato jurídico legal frente à extração minerária, o desfecho direcionado ao meio físico pode se traduzir em passivos ambientais, como lavras abandonadas, diferenciados na forma, tamanho e localização.

As áreas de estudo localizam-se às margens do Rio Itacaiúnas - Rodovia Transamazônica, na cidade de Marabá PA. São verificadas alterações topográficas que se instalaram com a exploração.

Na maioria das áreas, a cobertura vegetal atual está expressa, em sua quase totalidade, por uma vegetação de gramíneas (Brachiaria spp), algumas espécies de leguminosas arbóreas nativas e Babaçu (Orbignya phalerata) que medra sobre Latossolo Vermelho Amarelo fase argilosa.

As encostas no interior das cavas apresentam instabilidade física e química. A profundidade varia entre 6 e 8 metros, apresentando em sua porção distal espelhos d’água perene como nível de base local, abrangendo perímetro de variados metros. As bordas do espelho d'água são povoadas por "taboas" vegetação está bastante corrente em ambientes de brejo.

Os terrenos onde estão inseridos os passivos, não se encontram conectados à rede de drenagem superficial, apresentando um "alagamento" quase estático, desenvolvendo uma situação propicia a se tornar um criadouro de insetos, peixes e anfíbios e animais peçonhentos.

Neste cenário de degradação, surgem também os conflitos sociais evidenciados pela depreciação dos imóveis com proximidade das áreas de extração, a intensificação do trafego de veículos pesados causando trepidações e abalos nas estruturas prediais, 
ocasionando a suspensão de partículas e poeiras nocivas à saúde da população ao entorno do empreendimento, interferindo na dinâmica local dos bairros afetados, na sua imagem e do olhar social marginalizando sobre estas áreas de influencias diretas dos empreendimentos. Assim, a atividade mineral em domínios urbanos favorece o embate social entre o empreendimento e a população circunvizinha.

A relação se torna mais difícil quando há no entorno da cava de extração, atividades econômicas fortes e diversificadas, como indústrias, atividades de lazer, condomínios, horticulturas e áreas de preservação ambiental. Quando não há meio de solucionar os conflitos, a situação só tende a aumentar a animosidade entre as partes envolvidas, sociedade civil e as organizações empreendedoras, chegando ao ponto de fechamento da cava ou destruição das áreas em reabilitação como as ocorridas nas áreas de extração das cerâmicas Bambu e Cerita, objeto deste estudo.

A dinâmica presente no território amazônico brasileiro é uma constante e seus reflexos são latentes na região a exemplo da Cidade de Marabá - Pará onde as questões aqui apresentadas demonstram que o atual modelo formatado para o desenvolvimento da região é insuficiente na geração de soluções para a questão ambiental.

Neste aspecto, uma contraproposta ao modelo de desenvolvimento empregado na região não pode separar o homem da natureza, isso implica em construir um modelo ecologicamente e politicamente, onde o olhar indissociável da relação degradação ambiental e social seja aplicado com o olhar da equidade nas relações. Isso implica não somente na ação da intervenção, natureza recurso, como agente de minimização dos impactos que afetam a região, mas como a construção de uma nova natureza, alicerçada na justiça ambiental (PORTOGONÇALVES, 2004; LATOUR, 2004).

O processo de degradação ambiental e desmatamento na região é muito mais complexo do que algo que se justifique devido ao aumento demográfico, revela basicamente um anexo de intenções, práticas e políticas de desenvolvimento seguida de interesses comerciais com o apoio do Estado (HALL, 1991).

Diante do exposto, segundo Hentz (2012), os danos causados ao meio ambiente decorrente da extração de argila na região metropolitana de Marabá são em primeiro momento, prioritariamente de natureza física, porém seus efeitos e suas interações com a dinâmica do meio representam a mais grave agressão ao meio socioambiental (meio físico, meio biológico, meio social e meio econômico).

Assim, insere-se o polo cerâmico de Marabá que apresenta ainda na sua base de influência das ações mineradoras a pressão urbana no desenvolvimento de suas atividades, devido a grande maioria dos empreendimentos estarem instalados em áreas de expansão territorial urbana.

Assim, quando formas diferentes no uso do espaço se deparam, os conflitos passam a existir; sejam por disputas econômicas, sociais, ambientais e territoriais no uso dos recursos existentes. Esse contexto é sensivelmente percebido quando se trata da região metropolitana de Marabá - PA.

A fragilidade da atuação dos órgãos ambientais locais em 2007 levou a 
necessidade de intervenção do Ministério Público do Estado do Pará sobre a atividade de mineração de argila na cidade, exigindo através do Sindicado das Cerâmicas Vermelhas de Marabá SINDCERV, a necessidade de recuperação das áreas degradadas, sob força da lei Federal prevista no artigo 225 da Constituição Federal, (BRASIL, 1988), uma vez que as áreas após a extração da argila eram abandonadas causando degradação ambiental e problemas sociais, como morte de crianças, criação de animais peçonhentos, disseminação de doenças devido aos vetores que se multiplicavam nas águas paradas.

\section{CONCLUSÃO}

Este trabalho alertou a respeito da questão dos passivos ambientais oriundos da extração de argila, importante recurso mineral destinado à construção civil que o Brasil figura entre os maiores exportadores mundiais. Consequência de tal fato se refere às contrapartidas ambientais que se encerram diante da exploração, e que se impõe em diferentes modalidades de impactos no meio físico, conforme a natureza do material extraído e as condições de exploração.

Quando a exploração mineral é processada em áreas urbanas, os desfechos negativos no meio físico são somados os impactos de cunho social. Conforme a modalidade exploratória, a mineração pode desencadear poluição atmosférica, sonora, visual, dos recursos hídricos, afetando a sociedade em diferentes níveis.

O passivo ambiental toma forma com o encerramento da prática exploratória, que pode se dar em decorrência da exaustão da jazida, da inviabilidade econômica da exploração ou por efeito de intervenção do poder público. A esse respeito, o trabalho procurou apontar a possibilidade de recuperação de um tipo específico de passivo ambiental, notadamente as cavas abandonadas de extração de argila. $\bigcirc$ panorama prognosticado leva em conta a estabilidade do terreno e é de simples execução, podendo ser estendido para outras situações similares, onde as condições de estabilidade físico-química, disposição e tamanho da cava forem permissíveis.

\section{REFERÊNCIAS}

ALBUQUERQUE, J. A.; ARGENTON, J.; FONTANA, E. C.; COSTA, F. S.; RECH, T. D. Propriedades físicas e químicas de solos incubados com resíduo alcalino da indústria de celulose. Revista Brasileira de Ciência do Solo, v. 26, p. 1065-1073, 2002.

ALMEIDA, M. Caracterização Agrometeorológica do Município de Marabá. Trabalho de Conclusão de Curso apresentado à Faculdade de Ciências Agrárias da Universidade Federal do Pará, Marabá, 2007. 118 p.

\section{ALVES, J. C. L. Ocupação urbana e} impactos ambientais: Vicente Pires - o reverso da ocupação irregular em Brasília. Dissertação apresentada ao Programa de pós-graduação em Sociedade, Tecnologia e Meio Ambiente - Centro Universitário de Anápolis - UniEvangélica, 2011, 106 p.

BECKER, B. Amazônia. São Paulo: Editora Ática (Série Princípio), 1998.

BRASIL. Constituição da República Federativa Brasileira, Capítulo VI - Do 
Meio Ambiente, Diário Oficial da República Federativa do Brasil, Brasília, DF, 05 de outubro de 1988. 33a Edição, atualizada e ampliada, Editora Saraiva, São Paulo, 377 p.

BRASIL. Decreto Federal Nº 97.632, de 10 de março de 1989. Disponível em < http://4ccr.pgr.mpf.gov.br/institucional/gr upos-de-

traba/gtaguas/docs_legislacao/decreto_le i_97632.pdf>. Acesso em 21 Ago. 2014.

BRASIL. Lei de Crimes Ambientais, $N^{\circ}$ 9.605 de 12 de fevereiro de 1998. Disponível em $<$ http://w.ibama.gov.br/fauna/legislacao/l ei_9605_98.pdf>. Acesso em 21 Ago. 2014.

COELHO, M.C. N.; Costa, R. G. (orgs.). 10 Anos da Estrada de Ferro Carajás. Belém: UFPA/NAEA, Editora Gráfica Superiores, 1997.

CUNHA, S. T.; GUERRA, A. J. A Questão Ambiental: diferentes abordagens. 2. ed. Rio de Janeiro: Bertrand Brasil. 2005. 248p.

FARIAS, C. GOMES, E. Mineração e Meio Ambiente no Brasil. Pnud, 2002.

GUERRA, A. J. T.; MARÇAL, M. dos S. Geomorfologia Ambiental. 3. ed. Rio de Janeiro: Bertrand do Brasil, 2006.

HALL, A. L. Amazônia, desenvolvimento para quem? Desmatamento e conflito social no programa grande Carajás. Editora; Jorge Zahar, 1991.

HÉBETTE, J. Cruzando a fronteira: 30 anos de estudo do campesinato na Amazônia. Belém: EDUFPA, 2004.

HEIDRICH, Á. L. "Territorialidades de exclusão e inclusão social". In: REGO, N.,
MOLL, J.; AIGNER, C. (Orgs.) Saberes e práticas na construção de sujeitos sociais. Porto Alegre: Editora da UFRGS, 2004, p. 21-44.

HENTZ, A. M. Projeto de reabilitação de áreas degradadas através da produção das mudas de espécies florestais nativas inoculadas com fungos micorrízicos arbusculares. Convênio UFPA e Sindicato das Cerâmicas Vermelhas de Marabá-PA. 2012.

INSTITUTO BRASILEIRO DE GEOGRAFIA E ESTATÍ́STICA - IBGE. Sinopse do Censo Demográfico 2010. Disponível em: $<$ http://www.censo2010.ibge.gov.br/sino pse/index . php?uf $=41 \&$ dados $=0>$. Acesso em: 31 Abr. 2012.

LATOUR, B. Políticas da Natureza: como fazer ciência na democracia. Trad. de Carlos Aurélio Mota de Souza. Bauru, SP: Edusc, 2004. 411p.

LIPIETZ, A. O capital e seu espaço. Editora Nobel, São Paulo. 1987.

MONTEIRO, M. A. Mineração industrial na Amazônia e suas implicações para o desenvolvimento regional. Belém: NAEA/UFPA. 2006. p. 141-187.

NUNES, A. L. B. P.; CUNHA, A. M. de O.; MARÇAL JUNIOR, O. Coletores de lixo e enteroparasitoses: 0 papel das representações sociais em suas atitudes preventivas. Ciência e Educação, Bauru, v. 12, n. 1, abr. 2006.

PICOLI, F. O capital e a devastação da Amazônia. $1^{\text {a }}$ ed. - São Paulo: Expressão PORTO-GONÇALVES, C. W. O desafio ambiental. Rio de Janeiro: Record, 2004. 
REGENSBURGER, B. Recuperação de áreas degradadas pela mineração de argila através da regularização topográfica, da adição de insumos e serapilheira, e de atratores de fauna. 2004. Dissertação (Mestrado). Universidade Federal de Santa Catarina, 2004.

ROSA, J. C. S.; SANTOS, S. I. de A.; PEREIRA, D. C. O acúmulo de lixo no aglomerado da Serra: Uma visão de comunidades do entorno do Parque Municipal das Manganeiras. Revista Sinapse Ambiental. v. 7, n. 2, dez. 2010.

SALVADOR, A. R. F; MIRANDA, J. S. Recuperação de áreas degradadas. IETEC, 2007.

SÁNCHEZ, L. E. Avaliação de Impacto Ambiental: Conceitos e Métodos. São Paulo: Oficina de textos, p. 495, 2008.

SILVA, S. P. R. Considerações sobre o Estado e sua atuação sobre o território. Revista Espaço Acadêmico, n. 124, set. 2011.

VALICHESKI, R. R.; MARCIANO, C. R.; POCIANO, N. J. Avaliação econômica da reutilização de áreas degradadas pela extração de argila em Campos dos Goytacazes - RJ. Revista Ceres, v. 56, n. 1, 2009. 